\title{
Deficiency of vitamins $C$ and $E$ in women of childbearing age in Brazil: a systematic review and meta-analysis
}

\author{
Rosa Camila Lucchetta', Sophia de Andrade Cavicchioli", Ana Luísa Rodriguez Gini"', Marcela Forgerini"v, \\ Fabiana Rossi Varallo ${ }^{v}$, Mariane Nunes de Nadaiv", Fernando Fernandez-Llimos ${ }^{\mathrm{VII}}$, Patricia de Carvalho Mastroianni ${ }^{\mathrm{VII}}$
}

School of Pharmaceutical Sciences, Universidade Estadual Paulista (UNESP), São Paulo (SP), Brazil

IPhD. Pharmacist and Postdoctoral Researcher, Department of Drugs and Medicines, School of Pharmaceutical Sciences, Universidade Estadual Paulista (UNESP), São Paulo (SP), Brazil.

(D) https://orcid.org/0000-0002-4004-1320

"Undergraduate Student, Universidade de Araraquara (UNIARA), Araraquara (SP), Brazil.

(D) https://orcid.org/0000-0002-4922-4131

"'Undergraduate Student, Department of Drugs and Medicines, School of Pharmaceutical Sciences, Universidade Estadual Paulista (UNESP), São Paulo (SP), Brazil.

(D) https://orcid.org/0000-0003-2643-810X

vPharmacist and Doctoral Student, Department of Drugs and Medicines, School of Pharmaceutical Sciences, Universidade Estadual Paulista (UNESP), São Paulo (SP), Brazil.

(D) https://orcid.org/0000-0002-2905-8519

vPhD. Pharmacist and Professor, Department of Pharmaceutical Sciences, Faculdade de Ciências Farmacêuticas de Ribeirão Preto, Universidade de São Paulo (FCFRP-USP), Ribeirão Preto (SP), Brazil.

(D) https://orcid.org/0000-0003-4016-1442

"MD, PhD. Professor, Faculdade de Odontologia de Bauru, Universidade de São Paulo (FOB-USP), Bauru (SP), Brazil. (D) https://orcid.org/0000-0002-6706-7117

VIIPhD. Pharmacist and Professor, CINTESIS - Center for Health Technology and Services Research, Laboratory of Pharmacology, Department of Drug Sciences, Faculty of Pharmacy, Universidade do Porto, Porto, Portugal.

(D) https://orcid.org/0000-0002-8529-9595

WilPhD. Pharmacist and Professor, Department of Drugs and Medicines, School of Pharmaceutical Sciences, Universidade Estadual Paulista (UNESP), São Paulo (SP), Brazil.

(D) https://orcid.org/0000-0001-8467-7278

KEYWORDS (MeSH terms):

Alpha-tocopherol.

Ascorbic acid deficiency.

Women's health.

Cross-sectional studies.

Deficiency diseases.

Nutrition surveys.

Vitamin E deficiency.

\section{AUTHORS' KEYWORDS:}

Hypovitaminosis.

Lactating.

Nutritional epidemiology.

Maternal nutrition

\begin{abstract}
BACKGROUND: Despite the several options available for supplements containing vitamins $C$ and $E$, evidence regarding the prevalence of deficiency or insufficiency of these vitamins is weak.

OBJECTIVES: To estimate the prevalence of deficiency or insufficiency of vitamins $C$ and $E$ and associated factors among women of childbearing age, in Brazil.

DESIGN AND SETTING: Systematic review and meta-analysis conducted at a Brazilian public university. METHODS: A search from index inception until May 2020 was conducted. Meta-analyses were performed using inverse variance for fixed models, with summary proportions calculation using Freeman-Tukey double arcsine (base case). Reporting and methodological quality were assessed using the Joanna Briggs Institute tool for prevalence studies.

RESULTS: Our review identified 12 studies, comprising 1,316 participants, especially breastfeeding women. There was at least one quality weakness in all studies, mainly regarding sampling method (i.e. convenience sampling) and small sample size. The prevalence of vitamin C deficiency ranged from $0 \%$ to $40 \%$. Only vitamin E deficiency was synthetized in meta-analyses, with mean prevalences of $6 \%$ regardless of the alpha-tocopherol cutoff in plasma, and $5 \%$ and $16 \%$ for cutoffs of $<1.6-12.0 \mathrm{mmol} / / \mathrm{l}$ and $<16.2 \mathrm{mmol} / \mathrm{l}$, respectively. The cumulative meta-analysis suggested that a trend to lower prevalence of vitamin $\mathrm{E}$ deficiency occurred in recent studies.

CONCLUSIONS: Although the studies identified in this systematic review had poor methodological and reporting quality, mild-moderate vitamin $\mathrm{C}$ and $\mathrm{E}$ deficiencies were identified, especially in breastfeeding women. Thus, designing and implementing policies does not seem to be a priority, because the need has not been properly dimensioned among women of childbearing age in Brazil.
\end{abstract}

REGISTRATION NUMBER IN PROSPERO: CRD42020221605.

\section{INTRODUCTION}

Vitamins $\mathrm{C}$ and $\mathrm{E}$ are antioxidants agents and cofactors of various metabolic and enzymatic reactions. They also participate in several physiological processes, such as in repairing oxidative stress, antitumor processes and hormone production. ${ }^{1-3}$ Vitamins $\mathrm{C}$ and $\mathrm{E}$ also participate in human embryological development and their deficiency is associated with low weight in babies, prematurity, and malformations. ${ }^{4,5}$

Vitamin C and E deficiencies have also been correlated with occurrences of scurvy, anemia, hyperbilirubinemia, tiredness and depressive conditions. ${ }^{6,7}$ These deficiencies may occur because vitamins are not synthesized in the body, but are obtained through ingestion of vegetables, legumes, fruits and nuts, among other foods. ${ }^{8,9}$

Despite the recognized importance of these vitamins and the known risk of vitamin deficiencies, evidence among women of childbearing age is limited. The prevalence of vitamin $\mathrm{C}$ deficiency in adult women has been estimated to range from $6.9 \%$ in the United States to $14 \%$ in England, ${ }^{10}$ while vitamin E deficiency has been found to range from $20 \%$ to $90 \%$, depending on the population subgroup analyzed, the comorbidities presented and age. ${ }^{2}$ Some Brazilian primary studies have estimated that the prevalences of ascorbic acid ${ }^{11,12}$ and alpha-tocopherol ${ }^{13,14}$ deficiencies/insufficiencies are $30.8 \%$ and $62 \%-88.1 \%$ respectively, and have hypothesized that a problem of regional relevance may exist.

Studies eliciting the prevalence of a condition reflect the burden of this condition on society, and they assist in defining priorities for healthcare policies and decision-making. Well-designed 
cross-sectional studies are the most appropriate study design for estimating prevalence. If conducting these primary studies is not feasible, a systematic review gathering together the existing data may be the most appropriate approach for providing an idea of the magnitude of the problem and for achieving greater national representativeness. ${ }^{15}$

To our knowledge, no systematic review on this topic considering Brazilian data exists.

\section{OBJECTIVE}

The aim of this study was to estimate the prevalences of vitamins $\mathrm{C}$ and $\mathrm{E}$ deficiencies or insufficiencies and their associated factors, among women of childbearing age in Brazil.

\section{METHODS}

\section{Study design, protocol and registration}

A systematic review was performed in accordance with the recommendations of the Cochrane Collaboration, ${ }^{16}$ Meta-analysis of Observational Studies in Epidemiology (MOOSE) ${ }^{17}$ and Joanna Briggs Institute (JBI). ${ }^{18}$ The results were reported in accordance with the Preferred Reporting Items for Systematic Reviews and MetaAnalyses (PRISMA). ${ }^{19}$ The protocol for this review is available at $\mathrm{OSF}^{20}$ and PROSPERO (CRD42020221605). This study forms part of a larger study that evaluated vitamin A, B, C, D and E, calcium, iodine, iron and zinc deficiencies in women of childbearing age in Brazil.

\section{Information sources, search strategy and eligibility criteria}

Electronic searches were conducted through a pre-defined search strategy, which was described in the protocol, ${ }^{20}$ in the following databases: PubMed, LILACS, WHO, CAPES dissertations and theses (gray literature) and Scopus. ${ }^{21}$ The search encompassed the entire period from database inception to May 2020. The reference lists of reviews and studies that were included were also searched.

Studies that fulfilled the following inclusion criteria, in accordance with the CoCoPop acronym, ${ }^{22}$ were included: i) Condition: vitamin $\mathrm{C}$ and $\mathrm{E}$ deficiency or insufficiency; ii) Context: Brazil without restriction of setting; and iii) Population: women of childbearing age ( 15 to 49 years old) without any restriction on diseases or physiological status (i.e. non-pregnant, pregnant or breastfeeding). Data from studies that reported the deficiencies of interest using a different population classification (e.g. women aged 15 to 44 or pregnant teenagers) or different laboratory parameters, were separated for appropriate subgroup analyses.

Although cross-sectional studies are the ideal and are the study design most used for reporting prevalence, many studies have the potential to report this parameter, such as national surveys or longitudinal studies. Thus, all types of studies were included, except reviews, letters, comments, reports and case series. No language restriction was applied.

\section{Study selection and data extraction}

Two researchers independently screened the titles and abstracts and evaluated the full-text articles. Discrepancies were resolved through consensus meetings, using another researcher as a referee. The eligibility process was conducted using spreadsheets.

The following data were independently extracted by five researchers: (i) study characteristics (type of study, analysis period and state), characteristic of the population (e.g. pregnant women), micronutrient deficiency, sampling method and funding; (ii) participants' characteristics, i.e. ethnicity, comorbidities, drug therapy or supplement in use, body mass index (BMI), age, education and per capita income; and (iii) prevalence estimates (n/N (\%)) for the total population and for subgroups when available.

\section{Methodological quality in individual studies}

Given that no validated tool for assessing the risk of bias in prevalence studies exists, an assessment of the methodological and reporting quality based on the JBI Critical Appraisal Checklist for studies reporting prevalence data ${ }^{27}$ was conducted. The methodological rigor and completeness of the most critical domains were considered. ${ }^{28}$ The evaluation was performed independently by two reviewers. In the absence of consensus, points of disagreement were resolved by seeking the opinion of another investigator.

\section{Synthesis of results}

Although no predefined cutoffs for assessing deficiencies of vitamins $\mathrm{C}$ and $\mathrm{E}$ were considered as inclusion criteria in the present review, only studies that considered the same cutoff were grouped.

The data synthesis was primarily done through meta-analysis. Transitivity assessment was performed by comparing CoCoPop acronyms ${ }^{22}$ between studies (population inclusion and exclusion criteria and subpopulation definitions). If important discrepancies were identified, sensitivity analyses with the exclusion of the study in question were performed. To conduct direct meta-analyses, the data collected were transferred and analyzed separately in the $\mathrm{R}$ software, version 3.6.3 ( $\mathrm{R}$ studio 1.2.5033), ${ }^{23}$ using the READR ${ }^{24}$ and META packages. ${ }^{25}$

Direct proportional meta-analyses were conducted using the inverse variance method (base case) and GLMM method (sensitivity analysis). ${ }^{25}$ To calculate weighted summary proportions, Freeman-Tukey double arcsine transformation (PFT) (base case) and Logit transformation (PLOGIT) (sensitivity analysis) were considered in fixed-effect models (base case) and random-effect models (sensitivity analysis). ${ }^{19,25}$ Although high heterogeneity was expected and, therefore, a random-effect model could be expected, it has been recommended that a fixed-effect model is preferable for assessing prevalence, because otherwise the weighting will 
not properly consider the weights of the studies. ${ }^{26}$ Thus, analyses were conducted using both models, and potential differences were discussed.

The results from the meta-analysis were given as the proportion combined with its $95 \%$ confidence interval (CI), along with a list of the proportions (presented as percentages) with their respective 95\% CI that had been found in the individual studies included in the meta-analysis. A Higgins inconsistency test $\left(\mathrm{I}^{2}\right)$ with an estimator for $\operatorname{tau}^{2}$ was used through the DerSimonian-Laird method (base case), with statistical adjustment by means of Hartung and Knapp to a random model (sensitivity analysis).

A cumulative meta-analysis was carried out to assess changes and trends over time and to highlight emerging or decreasing conditions, along with their potential relationship with public policies that had been implemented.

Sensitivity analyses were performed by means of the leave-oneout method. Subgroup and meta-regression analyses, considering the period of analysis, state and region of Brazil, comorbidities, age or status (i.e. non-pregnant, pregnant or breastfeeding) were planned for meta-analyses with at least 10 studies. Alternative statistical methods were also conducted to validate the conclusions. Potential publication bias was assessed using rank tests (base case) and linear regression or the method of moments (sensitivity analysis), with at least 10 studies per meta-analysis. ${ }^{25}$

\section{Data sharing and data accessibility}

The data that support the findings of this study are openly available in OSF at http://doi.org/10.17605/OSF.IO/J9QMH. ${ }^{20}$

\section{RESULTS}

\section{Selection process}

Our systematic review identified 1,977 records in the electronic databases after removal of duplicates (PubMed, LILACS and Scopus) and 91 additional records identified through other sources (manual search, WHO database and CAPES database of dissertations and theses). Through the selection process, 259 published papers were included in the systematic review regardless of the micronutrient assessed. These included 12 studies (14 papers) about vitamins $\mathrm{C}$ and $\mathrm{E}$ (see supplementary data: Figure S1 and Table S2, available in OSF: https://osf.io/j9qmh/), ${ }^{20}$ consisting of eight cross-sectional studies, three prospective cohorts and one randomized clinical trial (Table 1).

\section{Characteristics of studies and participants}

The studies were conducted between 2002 and 2017, in cities in the northeastern region $(\mathrm{n}=8)$ and southeastern region $(\mathrm{n}=4)$, among women who were selected mainly from maternity clinics $(n=5)$ and hospitals $(n=4)$. Only Gurgel et al. ${ }^{29}$ reported that they used convenience sampling, while the sampling method was not reported in the remaining 11 studies. This lack of information may point towards use of convenience sampling. All the studies received some funding (Table $\mathbf{1}$ ).

A total of 1,316 participants were included, and the majority were breastfeeding $(n=1,037)$, with mean ages in the different studies ranging from 16.9 to 30.0 years. Most of the studies included healthy women or excluded women with chronic or infectious diseases $(n=9)$, and also excluded participants using supplements containing vitamin $C$ or $E(n=9)$. No study reported prevalence among non-pregnant and non-breastfeeding women. Gurgel et al. ${ }^{29}$ did not report on the use of medicines or supplements and Monteiro et al. ${ }^{30}$ only reported on the use of antiretroviral therapy. Furthermore, most of the studies did not report mean BMI, ethnicity, educational level or per capita income. Only five studies ${ }^{11,31-35}$ reported on the participants' educational level, and showed that the majority had low levels (data not shown). Six studies ${ }^{11,12,32-36}$ reported on per capita income and showed that the majority of the participants had monthly per capita income of less than one minimum wage (data not shown). The main characteristics of the participants are described in Table 1.

\section{Quality assessment}

In the quality assessments, all studies presented at least one 'No' answer, which suggests that, overall, there was poor reporting or methodological quality. The main questions with 'No' answers were in relation to the following: the sampling method, since most studies used convenience samples; the sample size, due to non-reporting of a target; the description of the subjects and setting, due to absence of information on ethnicity, comorbidities, BMI, educational level or per capita income; and lack of appropriate statistical analysis, e.g. not taking into account the number of participants with events or the total number of participants observed).

The response rate was considered unclear with regard to most studies assessing vitamin $\mathrm{E}$ and, consequently, no reliable estimate of vitamin E deficiency could be made. Considering that an adequate sample size depends on an estimate of prevalence, the estimated prevalence will directly influence the adequate response rate. For instance, if a prevalence of vitamin $\mathrm{E}$ deficiency of up to $6 \%$ is assumed, most of the studies achieved an adequate response rate. However, if a prevalence of at least $17 \%$ is assumed, none of the studies included presented an adequate response rate.

The questions for which all the answers were 'Yes' were in relation to the sample frame and validity of methods used for identifying the deficiencies. A detailed assessment of the methodological quality of the studies included is presented in Table 2. 
Table 1. Description of the characteristics of the studies included and participants

\begin{tabular}{|c|c|c|c|c|c|c|c|c|c|c|}
\hline Study & $\begin{array}{l}\text { Study } \\
\text { type }\end{array}$ & Vitamins & $\begin{array}{l}\text { Inclusion } \\
\text { period }\end{array}$ & $\begin{array}{l}\text { State/ } \\
\text { region }\end{array}$ & Setting & Funding & $\begin{array}{c}\text { Characteristic } \\
\text { (n) }\end{array}$ & Comorbidities & $\begin{array}{c}\text { Mean BMI, } \\
\mathrm{kg} / \mathrm{m}^{2}( \pm \\
\text { SD) }\end{array}$ & $\begin{array}{c}\text { Mean age, } \\
\text { years }( \pm \\
\text { SD) }\end{array}$ \\
\hline $\begin{array}{l}\text { Madruga } \\
\text { de Oliveira } \\
\text { A et al. }{ }^{11,32}\end{array}$ & $\mathrm{CS}$ & C & 2002 & $\begin{array}{c}\text { SP/ } \\
\text { southeast }\end{array}$ & Maternity & $\mathrm{CNPq}$ & $\begin{array}{c}\text { Pregnant } \\
\text { smokers (40); } \\
\text { pregnant } \\
\text { nonsmokers } \\
\text { (87); and } \\
\text { breastfeeding } \\
(117)\end{array}$ & Healthy & NR & $\begin{array}{l}\text { NR/20- } \\
34 \text { years } \\
(77.0 \%)\end{array}$ \\
\hline $\begin{array}{l}\text { Machado } \\
\text { et al. }{ }^{12}\end{array}$ & $\mathrm{CS}$ & $\mathrm{C}$ and $\mathrm{E}$ & $\begin{array}{l}2010- \\
2011\end{array}$ & $\begin{array}{c}\text { SP/ } \\
\text { southeast }\end{array}$ & Outpatient & UNIFESP & Pregnant (49) & $\mathrm{HIV}_{+}$ & NR & $30.0(6.5)$ \\
\hline $\begin{array}{l}\text { de Azeredo } \\
\text { and Trugo }{ }^{14}\end{array}$ & $\mathrm{CS}$ & $E$ & $N R$ & $\begin{array}{c}\mathrm{RJ} / \\
\text { southeast }\end{array}$ & Hospital & $\begin{array}{c}\text { CNPq, } \\
\text { FAPERJ, } \\
\text { and CAPES }\end{array}$ & $\begin{array}{c}\text { Breastfeeding } \\
\text { teenagers } \\
(72)\end{array}$ & Healthy & $23.1(3.2)$ & $16.9(1.4)$ \\
\hline $\begin{array}{l}\text { Clemente } \\
\text { et al. }{ }^{31}\end{array}$ & $\mathrm{RCT}$ & $E$ & $\begin{array}{l}2012- \\
2013\end{array}$ & $\begin{array}{c}\text { RN/ } \\
\text { northeast }\end{array}$ & $\begin{array}{c}\text { Maternity } \\
\text { hospital }\end{array}$ & CNPq & $\begin{array}{l}\text { Breastfeeding } \\
\text { (109) }\end{array}$ & Healthy & NR & $24.1(5.6)$ \\
\hline $\begin{array}{l}\text { de Lira } \\
\text { et al. }{ }^{37,39}\end{array}$ & $\mathrm{CS}$ & $E$ & 2010 & $\begin{array}{c}\text { RN/ } \\
\text { northeast }\end{array}$ & Hospital & $\mathrm{CNPq}$ & $\begin{array}{l}\text { Breastfeeding } \\
\qquad(103)\end{array}$ & $\begin{array}{c}\text { NR (some } \\
\text { chronic and } \\
\text { infectious } \\
\text { diseases were } \\
\text { excluded) }\end{array}$ & NR & $\begin{array}{c}24.0 \\
(7.0) / 14 \text { to } \\
41 \text { years }\end{array}$ \\
\hline $\begin{array}{l}\text { Garcia } \\
\text { et al. }{ }^{38}\end{array}$ & $\mathrm{CS}$ & $\mathrm{E}$ & 2008 & $\begin{array}{c}\text { RN/ } \\
\text { northeast }\end{array}$ & $\begin{array}{l}\text { Maternity } \\
\text { hospital }\end{array}$ & CNPq & $\begin{array}{l}\text { Breastfeeding } \\
\text { (32) }\end{array}$ & $\begin{array}{c}\text { NR (some } \\
\text { chronic } \\
\text { diseases were } \\
\text { excluded) }\end{array}$ & NR & $\begin{array}{c}25.0 \\
(6.3) / 14 \text { to } \\
36 \text { years }\end{array}$ \\
\hline $\begin{array}{l}\text { Gurgel } \\
\text { et al. }\end{array}$ & $\mathrm{CS}$ & $\mathrm{E}$ & $\begin{array}{l}2009- \\
2011\end{array}$ & $\begin{array}{c}\text { RN/ } \\
\text { northeast }\end{array}$ & $\begin{array}{c}\text { Maternity } \\
\text { hospital }\end{array}$ & UFRN & $\begin{array}{c}\text { Breastfeeding } \\
\text { (209) }\end{array}$ & Healthy & NR & $\begin{array}{c}\mathrm{NR} / 14 \text { to } 45 \\
\text { years }\end{array}$ \\
\hline $\begin{array}{l}\text { Monteiro } \\
\text { et al. } .^{30}\end{array}$ & $\mathrm{PC}$ & $\mathrm{E}$ & $N R$ & $\begin{array}{l}\text { SP and RJ/ } \\
\text { southeast }\end{array}$ & NR & $\mathrm{NICHD}$ & $\begin{array}{l}\text { Breastfeeding } \\
\text { (97) }\end{array}$ & $\mathrm{HIV}+$ & NR & $\begin{array}{c}\text { NR/20- } \\
29 \text { years } \\
(51.5 \%)\end{array}$ \\
\hline $\begin{array}{l}\text { da Silva } \\
\text { Ribeiro } \\
\text { et al. }{ }^{33}\end{array}$ & $\mathrm{CS}$ & $\mathrm{E}$ & $\begin{array}{l}2012- \\
2013\end{array}$ & $\begin{array}{c}\text { RN/ } \\
\text { northeast }\end{array}$ & Hospital & UFRN & $\begin{array}{l}\text { Breastfeeding } \\
\qquad(58)\end{array}$ & $\begin{array}{l}\text { NR (some } \\
\text { chronic and } \\
\text { infectious } \\
\text { diseases were } \\
\text { excluded) }\end{array}$ & $\begin{array}{c}\text { NR/around } \\
28.0\end{array}$ & $\begin{array}{c}\text { NR/around } \\
24.0\end{array}$ \\
\hline $\begin{array}{l}\text { Ribeiro } \\
\text { et al. }^{34}\end{array}$ & $\mathrm{CS}$ & $\mathrm{E}$ & $\begin{array}{l}2013- \\
2014\end{array}$ & $\begin{array}{c}\text { RN/ } \\
\text { northeast }\end{array}$ & Hospital & UFRN & $\begin{array}{c}\text { Pregnant } \\
(103)\end{array}$ & $\begin{array}{l}\text { NR (some } \\
\text { chronic and } \\
\text { infectious } \\
\text { diseases were } \\
\text { excluded) }\end{array}$ & NR & $\begin{array}{l}\text { NR/18- } \\
24 \text { years } \\
(59.0 \%)\end{array}$ \\
\hline Rodrigues $^{36}$ & $\mathrm{PC}$ & $\mathrm{E}$ & $\begin{array}{l}2012- \\
2015\end{array}$ & $\begin{array}{c}\mathrm{RN} / \\
\text { northeast }\end{array}$ & $\begin{array}{c}\text { Maternity } \\
\text { hospital }\end{array}$ & UFRN & $\begin{array}{l}\text { Breastfeeding } \\
\text { (mothers of } \\
\text { children born } \\
\text { preterm and } \\
\text { at term) (124) }\end{array}$ & NR & $\begin{array}{c}\text { Mothers of } \\
\text { preterm: } \\
28.3 \\
\text { (5.2); and } \\
\text { mothers of } \\
\text { term: } 28.3 \\
(4.3)\end{array}$ & $\begin{array}{c}\text { Mothers of } \\
\text { preterm: } \\
26.0(6.7) ; \\
\text { and } \\
\text { mothers of } \\
\text { term: } 24.5 \\
(6.0)\end{array}$ \\
\hline $\begin{array}{l}\text { da Silva } \\
\text { et al. }{ }^{35}\end{array}$ & $\mathrm{PC}$ & $\mathrm{E}$ & $\begin{array}{l}2016- \\
2017\end{array}$ & $\begin{array}{c}\text { RN/ } \\
\text { northeast }\end{array}$ & Outpatient & UFRN & $\begin{array}{c}\text { Breastfeeding } \\
\text { (nonsmokers) } \\
\text { (116) }\end{array}$ & $\begin{array}{c}\text { NR (some } \\
\text { infectious } \\
\text { diseases were } \\
\text { excluded) }\end{array}$ & $N R$ & $27.8(7.4)$ \\
\hline
\end{tabular}

$\mathrm{BMI}=$ body mass index; $\mathrm{CAPES}=$ Coordenação de Aperfeiçoamento de Pessoal de Nível Superior; CNPq = Conselho Nacional de Desenvolvimento Científico e Tecnológico; CS = cross-sectional; FAPERJ = Fundação de Amparo à Pesquisa do Estado do Rio de Janeiro; HIV+ = human immunodeficiency virus-positive; NICHD = National Institute of Child Health and Human Development; $\mathrm{NR}=$ not reported; $\mathrm{PC}=$ prospective cohort; $\mathrm{RCT}$ = randomized clinical trial; $\mathrm{RJ}=$ Rio de Janeiro; $\mathrm{RN}=$ Rio Grande do Norte; SD = standard deviation; SP = São Paulo; UFRN = Universidade Federal do Rio Grande do Norte; UNIFESP = Universidade Federal de São Paulo. 


\section{Prevalence analysis}

Only two studies (three papers) were found to report on the prevalence of deficiency or insufficiency of vitamin C. . $^{11,12,32}$ These studies used different cutoffs for ascorbic acid in plasma and, therefore, it was not possible to include them in any metaanalysis. De Oliveira et al. ${ }^{11,32}$ used a cutoff of $<22.7 \mathrm{mmol} / \mathrm{l}(0.4$ $\mathrm{mg} / \mathrm{dl}$ ) and identified prevalences ranging from $27.0 \%$ (nonsmoker pregnant women) to $40.0 \%$ (smoker pregnant women), while Machado et al. ${ }^{12}$ found that the prevalence of vitamin $\mathrm{C}$ deficiency $(<11 \mathrm{mmol} / \mathrm{l})$ was $0 \%$, but that $12.2 \%$ of the pregnant women evaluated had suboptimal plasma levels (11-28 mmol/l).

Eleven studies reported on the prevalence of deficiency or insufficiency of vitamin E. ${ }^{12,14,29-31,33-39}$ Different cutoffs for alpha-tocopherol in plasma were used, but a meta-analysis with three subgroups could be conducted. Machado et al. ${ }^{12}$ and Monteiro et al. ${ }^{30}$ were not included in any vitamin E meta-analysis because their cutoffs of $<9.7 \mathrm{mmol} / \mathrm{l}$, 9.7-16.2 $\mathrm{mmol} / \mathrm{l}$ and $<7 \mathrm{mmol} / \mathrm{l}$ were not used in any other study. These two studies identified prevalences ranging from $0 \%$ to $22.4 \%$.

Among the eleven studies, the prevalence of vitamin E deficiency ranged from $0 \%$ to $62.5 \%$. Subgroup analyses were conducted on the mother's weight or BMI, age, gestational weight gain, parity, delivery type, public or private maternity hospital, days after delivery, preterm or term infant, educational level, housing type (rural or urban) and per capita income. No statistical differences in prevalence $(\mathrm{P}<0.05)$ were identified among these subgroups. No meta-analysis on these subgroup analyses was possible, either because only one study reported the subgroup or because different cutoffs were considered.
In the meta-analysis for the base case, an overall prevalence of $6 \%$ (95\% CI 5\%-8\%) was identified, while 5\% (95\% CI 4\%-7\%) and $16 \%$ (95\% CI 11\%-23\%) were estimated for the cutoffs of 11.6-12.0 mmol/l and $16.2 \mathrm{mmol} / \mathrm{l}$ cutoffs, respectively (Figure 1). A cumulative meta-analysis was performed considering the year of publication, and this showed a smaller trend of prevalence of vitamin E deficiency or insufficiency, with a slight join point in 2015 (Figure 2).

A sensitivity analysis using the leave-one-out method was conducted but was unable to reduce the heterogeneity (89\%-96\%), and the overall prevalence ranged from $4 \%$ to $8 \%$ (see supplementary data: Table S3, available in OSF: https://osf.io/j9qmh/). ${ }^{20}$ In this analysis, withdrawal of the study by Ribeiro et al., ${ }^{34}$ which was the only study that did not include breastfeeding women, resulted in a prevalence of vitamin E deficiency of 7\% (95\% CI 5\%-8\%), with $\mathrm{I}^{2}$ of $96 \%$. The studies with most influence on the variations were those of de Azeredo et al., ${ }^{14}$ on teenager breastfeeding, and Clemente et al., ${ }^{31}$ on breastfeeding in general. Sensitivity analyses using alternative statistical methods identified prevalences ranging from $8 \%$ to $17 \%$ (see supplementary data: Table S4, available in OSF: https://osf.io/j9qmh/). ${ }^{20}$

Meta-regression analyses were conducted on publication year $(\mathrm{P}<0.01)$ and cutoffs $(\mathrm{P}<0.001)$, and both of these variables explained the heterogeneity (Figure 3). No meta-regression or subgroup analyses on other variables was possible. It was also not possible to conduct statistical and visual analyses on publication bias for any meta-analysis because the requirements for a minimum number of studies or different results and sample sizes were not met.

Table 2. Methodological and reporting quality assessment, using Joanna Briggs Institute tool for prevalence studies

\begin{tabular}{|c|c|c|c|c|c|c|c|c|c|}
\hline \multirow{2}{*}{ Studies } & \multicolumn{9}{|c|}{ Questions } \\
\hline & 1 & 2 & 3 & 4 & 5 & 6 & 7 & 8 & 9 \\
\hline Madruga de Oliveira A et al. ${ }^{11,32}$ & Yes & $\mathrm{No}^{\mathrm{a}}$ & $\mathrm{No}^{c}$ & $\mathrm{No}^{d}$ & Unclear $^{d}$ & Yes & $\mathrm{NA}^{\mathrm{e}}$ & $\mathrm{No}^{f}$ & $\mathrm{No}^{g}$ \\
\hline Machado et al. ${ }^{12}$ & Yes & $\mathrm{No}^{\mathrm{a}}$ & $\mathrm{No}^{\mathrm{c}}$ & $\mathrm{No}^{d}$ & Unclear $^{d}$ & Yes & $\mathrm{NA}^{\mathrm{e}}$ & Yes & $\mathrm{No}^{\mathrm{g}}$ \\
\hline de Azeredo and Trugo. ${ }^{14}$ & Yes & $\mathrm{No}^{\mathrm{a}}$ & $\mathrm{No}^{c}$ & Yes & Yes & Yes & $\mathrm{NA}^{\mathrm{e}}$ & $\mathrm{No}^{f}$ & Unclear $^{\mathrm{h}}$ \\
\hline Clemente et al. ${ }^{31}$ & Yes & $\mathrm{No}^{\mathrm{a}}$ & $\mathrm{No}^{c}$ & $\mathrm{No}^{d}$ & Unclear $^{d}$ & Yes & $\mathrm{NA}^{\mathrm{e}}$ & Yes & Unclear $^{h}$ \\
\hline de Lira et al. ${ }^{37,39}$ & Yes & $\mathrm{No}^{\mathrm{a}}$ & $\mathrm{No}^{c}$ & $\mathrm{No}^{d}$ & Unclear $^{d}$ & Yes & $\mathrm{NA}^{\mathrm{e}}$ & $\mathrm{No}^{f}$ & Unclear $^{h}$ \\
\hline Garcia et al. ${ }^{38}$ & Yes & $\mathrm{No}^{\mathrm{a}}$ & $\mathrm{No}^{c}$ & $\mathrm{No}^{d}$ & Unclear $^{d}$ & Yes & $\mathrm{NA}^{\mathrm{e}}$ & Yes & Unclear $^{h}$ \\
\hline Gurgel et al. ${ }^{29}$ & Yes & $\mathrm{No}^{\mathrm{b}}$ & Yes & $\mathrm{No}^{d}$ & Unclear $^{d}$ & Yes & $\mathrm{NA}^{\mathrm{e}}$ & Yes & Unclear $^{\mathrm{h}}$ \\
\hline Monteiro et al..$^{30}$ & Yes & $\mathrm{No}^{\mathrm{a}}$ & $\mathrm{No}^{c}$ & $\mathrm{No}^{d}$ & Unclear $^{d}$ & Yes & $\mathrm{NA}^{\mathrm{e}}$ & Yes & Unclear $^{h}$ \\
\hline da Silva Ribeiro et al. ${ }^{33}$ & Yes & $\mathrm{No}^{\mathrm{a}}$ & $\mathrm{No}^{c}$ & $\mathrm{No}^{d}$ & Unclear $^{d}$ & Yes & $\mathrm{NA}^{\mathrm{e}}$ & $\mathrm{No}^{f}$ & Unclear $^{\mathrm{h}}$ \\
\hline Ribeiro et al. ${ }^{34}$ & Yes & $\mathrm{No}^{\mathrm{a}}$ & $\mathrm{No}^{c}$ & $\mathrm{No}^{d}$ & Unclear $^{d}$ & Yes & $\mathrm{NA}^{\mathrm{e}}$ & Yes & Unclear $^{\mathrm{h}}$ \\
\hline Rodrigues. $^{36}$ & Yes & $\mathrm{No}^{\mathrm{a}}$ & $\mathrm{No}^{c}$ & Yes & Yes & Yes & $\mathrm{NA}^{\mathrm{e}}$ & $\mathrm{No}^{f}$ & Unclear $^{\mathrm{h}}$ \\
\hline da Silva et al. ${ }^{35}$ & Yes & $\mathrm{No}^{\mathrm{a}}$ & $\mathrm{No}^{\mathrm{c}}$ & $\mathrm{No}^{d}$ & Uncleard & Yes & $N A^{e}$ & $\mathrm{No}^{f}$ & Unclear $^{\mathrm{h}}$ \\
\hline
\end{tabular}

1. Was the sample frame appropriate to address the target population? 2. Were study participants recruited in an appropriate way? 3. Was the sample size adequate? 4. Were the study subjects and setting described in detail? 5. Was data analysis conducted with sufficient coverage of the identified sample? 6. Were valid methods used for the identification of the condition? 7. Was the condition measured in a standard, reliable way for all participants? 8 . Was there appropriate statistical analysis? 9. Was the response rate adequate, and if not, was the low response rate managed appropriately?

NA = not applicable; a Not reported, but taken to have been convenience sampling; beported as convenience sampling; 'No target sample size was reported; ${ }^{d}$ Most of the studies did not report ethnicity, comorbidities, body mass index, age, educational level or per capita income; eNot applicable, since the methods were automated and highly replicable; ${ }^{\mathrm{N} N u m e r a t o r}(\mathrm{n})$ or denominator $(\mathrm{N})$ of prevalence was not reported; 9 These studies presented a response rate for vitamin C assessment of fewer than 320 participants; ${ }^{\text {hN }}$ o reliable estimate of vitamin E deficiency was possible: if a prevalence of $6 \%$ or less is assumed, most of the studies achieved an adequate response rate; however, if a prevalence of $17 \%$ or higher is assumed, none of the studies presented an adequate response rate. 


\section{DISCUSSION}

In this systematic review, twelve studies assessing the prevalence of vitamins $\mathrm{C}$ and $\mathrm{E}$ deficiency, especially among breastfeeding women, were identified. Two studies reported on vitamin C deficiency ( $0 \%$ to $40 \%)$ and eleven reported on vitamin E deficiency
( $0 \%$ to $62.5 \%$ ), with a mean prevalence of $6 \%$ identified through the meta-analysis. The low frequency of assessment of vitamin $\mathrm{C}$ and $\mathrm{E}$ deficiencies in the past may explain why no systematic review reporting the prevalence of deficiency of these vitamins was found. ${ }^{6}$ It is important to note that our findings suggest that

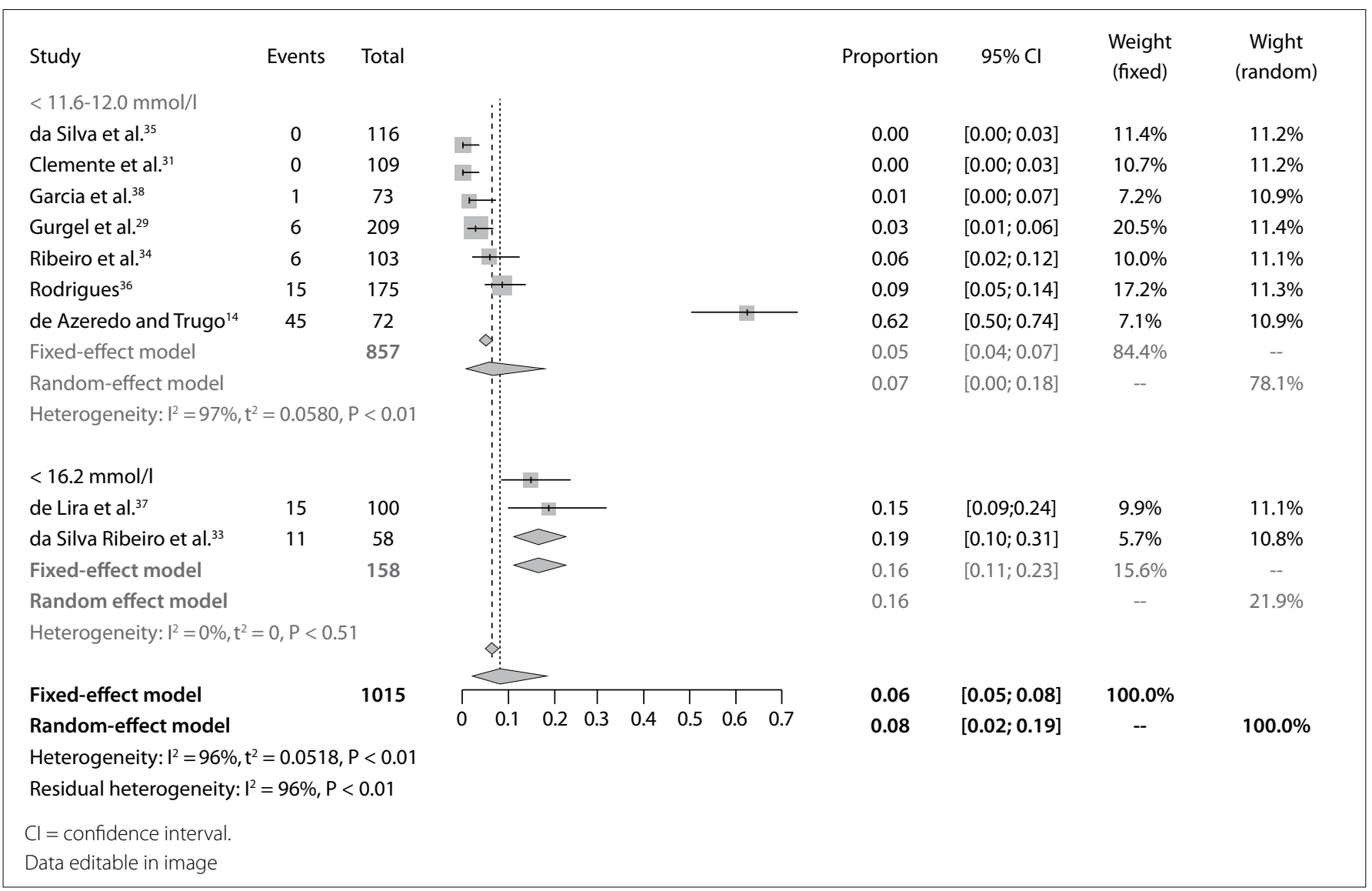

Figure 1. Forest plot for prevalence of vitamin E deficiency, according to alpha-tocopherol cutoff.

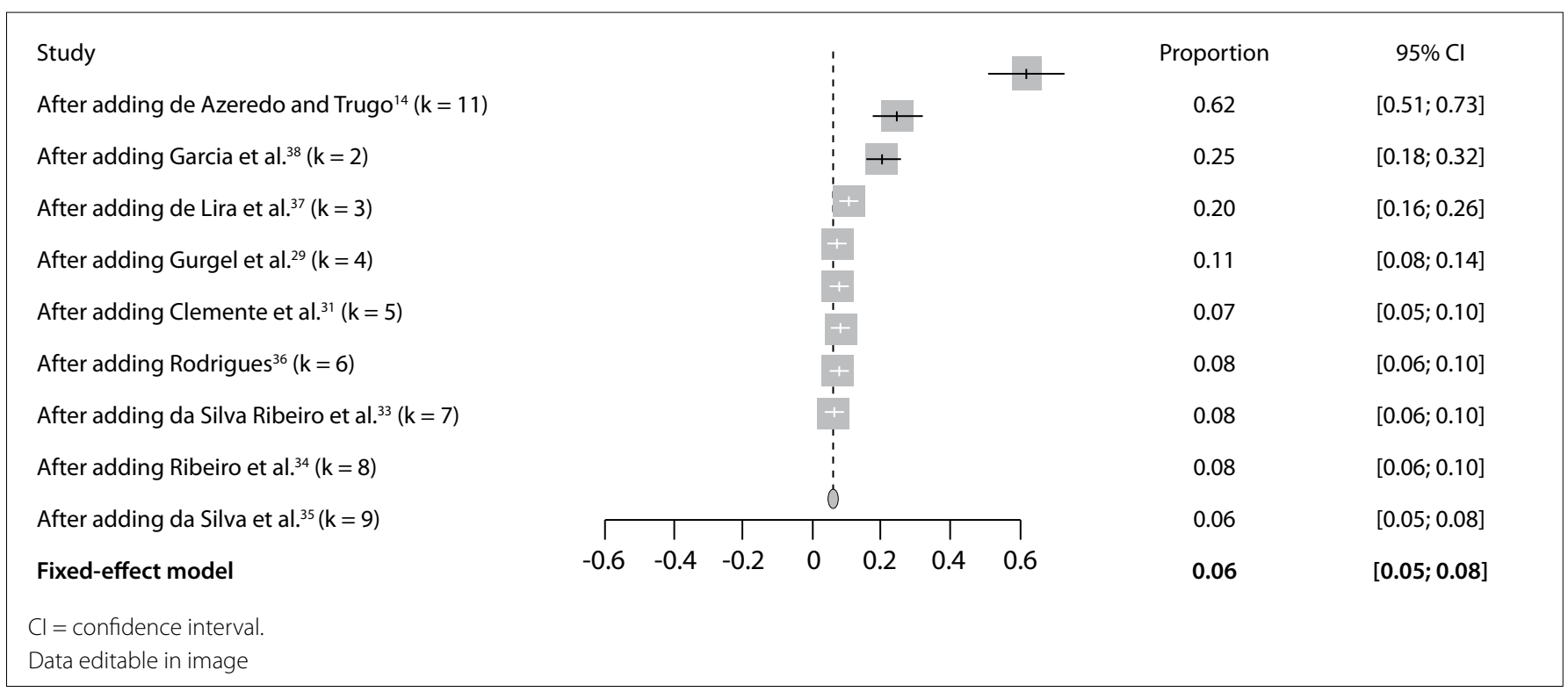

Figure 2. Forest plot for cumulative meta-analysis on prevalence of vitamin E deficiency, according to publication year. 
deficiency of vitamins $\mathrm{C}$ and $\mathrm{E}$ could constitute a public health problem in Brazil, depending on the study and the cutoff for plasma alpha-tocopherol or ascorbic acid under consideration.

It is likely that breastfeeding women have lower vitamin $\mathrm{C}$ status due to transfer of vitamin $\mathrm{C}$ to the growing infant via breastmilk..$^{40}$ Maternal intake of vitamin $\mathrm{C}$ in the diet but not as a supplement has been shown to determine the concentration of vitamin $\mathrm{C}$ in breast milk, ${ }^{41}$ and this was found to vary with season. Therefore, maternal ascorbic acid intake and education about healthy nutrition (consumption of vegetables and fruits) are important.

Furthermore, during pregnancy, placental transfer of vitamin E to the fetus is limited. Thus, breast milk is the only source of this nutrient for infants that are exclusively breastfed. ${ }^{42}$ The composition of human milk depends on the stage of breastfeeding, time of the day, time since last meal, nutrition, maternal age, gestational age of the newborn and other individual maternal factors. ${ }^{43}$ Therefore, it is important to diagnose deficiencies of vitamins $\mathrm{C}$ and $\mathrm{E}$ among breastfeeding women, since intake of these vitamins is an important way to supply the newborn with essential antioxidant protection and to stimulate immune system development. ${ }^{43}$

Indeed, insufficient evidence of deficiencies of vitamins $\mathrm{C}$ and E worldwide has led to a lack of definition of what constitutes adequate intake of these micronutrients. It has also led to use of different cutoffs for defining deficiency or insufficiency. As expected, in studies evaluating alpha-tocopherol (vitamin E), the higher the cutoff point was (alpha-tocopherol $<16.2 \mathrm{mmol} / \mathrm{l}$ ), the greater the prevalence of deficiency also was (16\%). This suggests that there is a need for studies to establish the cutoff taking into consideration the patients' clinical and physiological conditions (e.g. pregnant women, breastfeeding women or infants). It has, for instance, been found that maternal deficiency influenced the level of vitamin $\mathrm{E}$ in the umbilical cord, but not in the colostrum. This suggests that strategies for solving vitamin E deficiency should consider differences among pregnant and breastfeeding women. ${ }^{33}$

All the studies included here showed low reporting or methodological quality, thus producing findings with low confidence, mainly due to inappropriate sampling methods and sample sizes, which consequently did not provide representative samples of the base populations. High inconsistency was also identified, which further downgrades the confidence in the prevalence rates reported. These issues are common in observational studies. ${ }^{17,44,45}$ This high inconsistency suggested that the studies should not be included in the same meta-analysis because of their different evaluation methods (e.g. the methods used to assess deficiency) or participant characteristics (e.g. age, ethnicity, educational level, per capita income or sociodemographic factors). In fact, most of the studies did not report the characteristics of the participants, which made it impossible to conduct robust analyses for exploring the heterogeneity, or to identify possible factors associated with deficiency or insufficiency of vitamins $\mathrm{C}$ and $\mathrm{E}$.
Several options for vitamin supplements containing vitamins $\mathrm{C}$ and $\mathrm{E}$ are available in Brazil, and some of them are included in the Brazilian National List of Essential Medicines (RENAME). ${ }^{46}$ Distribution of sachets containing a mixture of micronutrients forms part of the Brazilian strategy for strengthening baby feeding with micronutrients in powder (NutriSUS) ${ }^{47}$ Moreover, policies for iron + folic acid ${ }^{48}$ and vitamin $\mathrm{A}^{49}$ supplementation for pregnant and breastfeeding women exist. Nonetheless, no national policy regarding supplementation with any other vitamin (e.g. C and E) exists.

On the other hand, little is known regarding the benefits of use of these supplements among pregnant women. A Cochrane systematic review found that routine supplementation with vitamin $\mathrm{E}$ in combination with other supplements, to prevent fetal

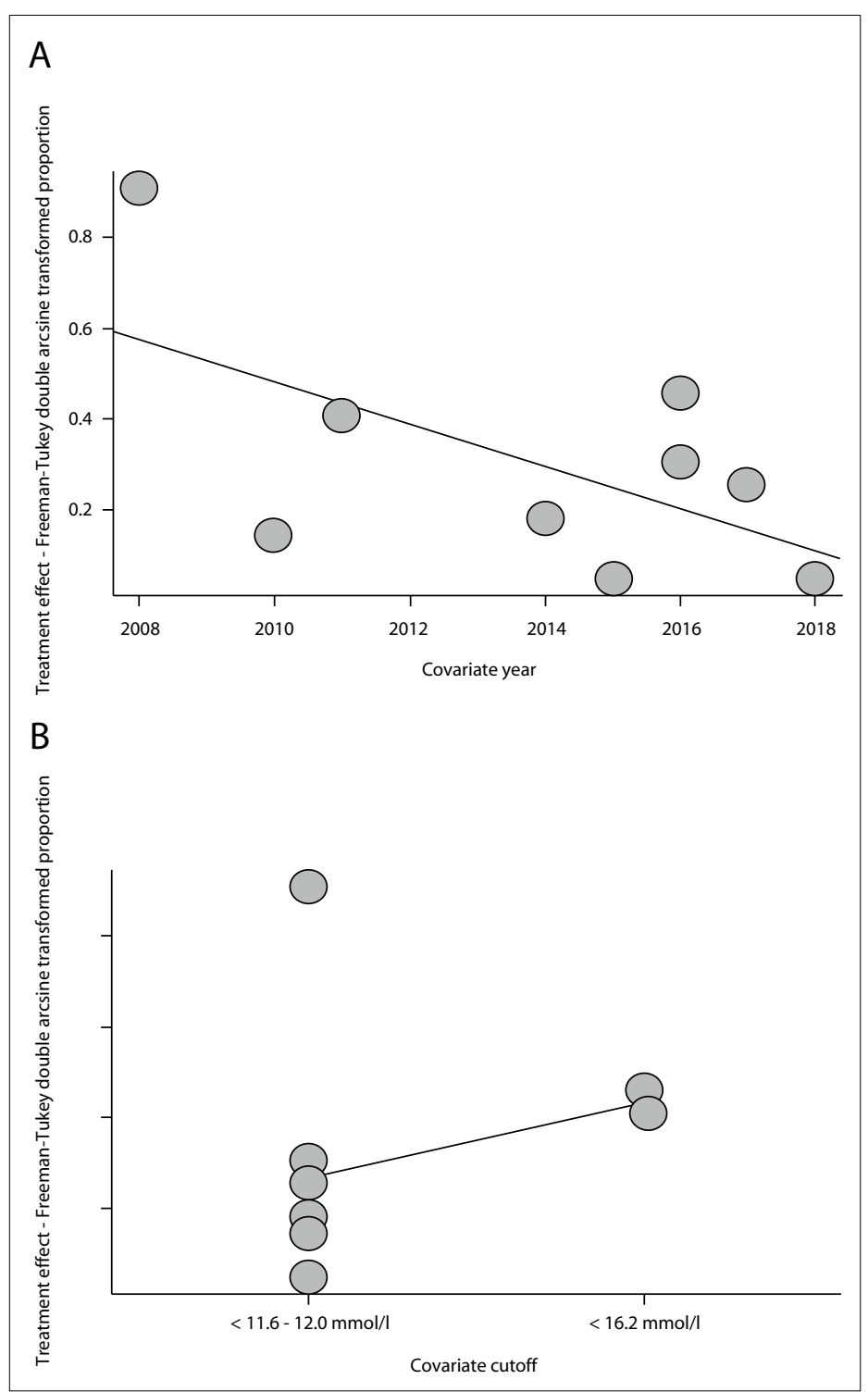

Figure 3. A) Meta-regression plot for publication year (vitamin $E$ deficiency); B) Meta-regression plot for alpha-tocopherol cutoff. 
death, neonatal death, premature birth, preeclampsia, premature rupture of membranes (at term or preterm) or fetal growth restriction, was not supported by the current data. ${ }^{6}$ Another systematic review, which assessed interventions consisting of vitamin $\mathrm{C}$ supplementation alone or in combination with other supplements, found that there was no reduction in prevention of fetal or neonatal death, poor fetal growth, preterm birth or pre-eclampsia. ${ }^{50}$ Therefore, it is important to assess the risks relating to deficiency of vitamins $\mathrm{C}$ and $\mathrm{E}$, as well as the benefits from supplementation of these vitamins.

The risk of hypervitaminosis ${ }^{51}$ or supplement-drug interactions has been documented. ${ }^{52,53}$ Drug interactions with vitamins can be of particular importance and are well documented. These include the following situations: beta-blockers may present reduced absorption if used concurrently with vitamin $\mathrm{C}$ supplementation; mineral oil and antacids containing aluminum hydroxide can reduce the absorption of fat-soluble vitamins; vitamin $\mathrm{C}$ supplementation can inhibit the action of some antibiotics; use of proton pump inhibitors can cause vitamin $\mathrm{C}$ deficiency; and excessive vitamin E supplementation can reduce the absorption of vitamins $A$ and K. ${ }^{52,53}$ Therefore, care should be taken with regard to irrational use of supplements through self-medication or prescription. Indeed, robust evidence to assess the problem of vitamin deficiencies and their outcomes among women is needed before establishing potential strategies.

One limitation of this study, like in any systematic review, was that some studies may have been missed. To overcome this limitation, extensive investigation of the gray literature and manual searches to find unpublished studies were conducted, which found several studies that had not been retrieved through electronic searches. This high number of studies identified through manual search might be seen as a limitation of the search strategy. However, one hypothesis for explaining this occurrence is that the titles and abstracts of many studies may have been inadequately drafted in relation to the study subject or may not have been correctly indexed, which might have hindered retrieval. Lastly, another limitation was the absence of robust analysis on the potential factors associated with vitamin $\mathrm{C}$ and $\mathrm{E}$ deficiencies, due to poor reporting and the small size of the meta-analyses (studies and participants).

\section{CONCLUSION}

Although the studies identified in this systematic review showed poor reporting and poor methodological quality, the current evidence suggests that a mild-to-moderate problem exists regarding the prevalence of deficiencies of vitamin $\mathrm{C}$ (ranging from $0 \%$ to $40 \%$ ) and vitamin E (5\% to $16 \%$ ), especially among breastfeeding women and in studies in Rio Grande do Norte. Thus, it seems that designing and implementing policies to address this problem is not seen as a national priority because the deficiency problem among women of childbearing age in Brazil is not accurately represented. Future studies should consider using standard cutoffs for plasma alpha-tocopherol and ascorbic acid, random probabilistic sampling, appropriate sample sizes and predefined subgroup analyses, in order to adequately inform the prevalences of deficiencies of vitamins $\mathrm{C}$ and $\mathrm{E}$ and associated factors among women of childbearing age (non-pregnant, pregnant and breastfeeding women), and to support potential healthcare policies.

\section{REFERENCES}

1. Pekmezci D. Vitamin E and immunity. Vitam Horm. 2011;86:179-215. PMID:21419272; https://doi.org/10.1016/B978-0-12-386960-9.00008-3.

2. Dror DK, Allen LH. Vitamin E deficiency in developing countries. Food Nutr Bull. 2011;32(2):124-43. PMID: 22164974; https://doi. org/10.1177/156482651103200206.

3. Ferraz L, Albiero C, Boechat SG, et al. Micronutrientes e sua importância no período gestacional. Revista Saber Científico. 2018;7(1):68-82. Available from: http://revista.saolucas.edu.br/index.php/resc/article/ view/787. Accessed in 2021 (Apr 23).

4. Wang $X$, Falcone $T$, Attaran $M$, et al. Vitamin $C$ and vitamin $E$ supplementation reduce oxidative stress-induced embryo toxicity and improve the blastocyst development rate. Fertil Steril. 2002;78(6):1272-7. PMID: 12477524; https://doi.org/10.1016/s0015-0282(02)04236-X.

5. Adlard BP, De Souza SW, Moon S. Ascorbic acid in fetal human brain. Arch Dis Child. 1974;49(4):278-82. PMID: 4830116; https://doi.org/10.1136/ adc.49.4.278.

6. Rumbold A, Ota E, Hori H, Miyazaki C, Crowther CA. Vitamin E supplementation in pregnancy. Cochrane Database Syst Rev. 2015;(9):CD004069. PMID: 26343254; https://doi.org/10.1002/14651858. CD004069.pub3.

7. Carr AC, Rosengrave PC, Bayer S, et al. Hypovitaminosis $C$ and vitamin C deficiency in critically ill patients despite recommended enteral and parenteral intakes. Crit Care. 2017;21(1):300. PMID: 29228951; https:// doi.org/10.1186/s13054-017-1891-y.

8. Sarni RO, Souza Fl, Cocco RR, Mallozi MC, Solé D. Micronutrientes e sistema imunológico [Micronutrients, immunologic system and allergic diseases]. Rev Bras Alerg Imunopatol. 2010;33(1):8-13. Available from: http://www.sbai.org.br/revistas/Vol331/ART\%201-10\%20-\%20 Micronutrientes\%20e\%20sistema\%20imunol\%C3\%B3gico.pdf. Accessed in 2021 (Apr 23).

9. Nishikimi M, Fukuyama R, Minoshima S, Shimizu N, Yagi K. Cloning and chromosomal mapping of the human nonfunctional gene for L-gulono-gamma-lactone oxidase, the enzyme for L-ascorbic acid biosynthesis missing in man. J Biol Chem. 1994;269(18):13685-8. PMID: 8175804.

10. Rowe S, Carr AC. Global Vitamin C Status and Prevalence of Deficiency: A Cause for Concern? Nutrients. 2020;12(7):2008. PMID: 32640674; https://doi.org/10.3390/nu12072008. 
11. Madruga de Oliveira A, Rondó PH, Mastroeni SS, Oliveira JM. Plasma concentrations of ascorbic acid in parturients from a hospital in Southeast Brazil. Clin Nutr. 2008;27(2):228-32. PMID: 18234398; https:// doi.org/10.1016/j.clnu.2007.11.006.

12. Machado RHV, Bonafe S, Castelo A, Patin RV. Vitamin profile of pregnant women living with HIV/AIDS. e-ESPEN Journal. 2013;8(3):e108-e112. https://doi.org/10.1016/j.clnme.2013.03.002.

13. Paes-Silva RP, Tomiya MTO, Maio R, et al. Prevalence and factors associated with fat-soluble vitamin deficiency in adolescents. Nutr Hosp. 2018;35(5):1153-62. PMID: 30307300; https://doi.org/10.20960/ nh. 1785 .

14. de Azeredo VB, Trugo NM. Retinol, carotenoids, and tocopherols in the milk of lactating adolescents and relationships with plasma concentrations. Nutrition. 2008;24(2):133-9. PMID: 18053685; https:// doi.org/10.1016/j.nut.2007.10.011.

15. Munn Z, Moola S, Lisy K, Riitano D, Tufanaru C. Methodological guidance for systematic reviews of observational epidemiological studies reporting prevalence and cumulative incidence data. Int J Evid Based Healthc. 2015;13(3):147-53. PMID: 26317388; https://doi.org/10.1097/ XEB.00000000000000054.

16. Higgins JPT, Thomas J, Chandler J, et al. Cochrane Handbook for Systematic Reviews of Interventions. $2^{\text {nd }}$ ed. Chichester (UK): John Wiley \& Sons, 2019.

17. Stroup DF, Berlin JA, Morton SC, et al. Meta-analysis of observational studies in epidemiology: a proposal for reporting. Meta-analysis Of Observational Studies in Epidemiology (MOOSE) group. JAMA. 2000;283(15):2008-12. PMID: 10789670; https://doi.org/10.1001/ jama.283.15.2008.

18. Lizarondo L, Stern C, Carrier J, et al. Chapter 8: Mixed methods systematic reviews. In: Aromataris E, Munn Z (Editors). JBI Manual for Evidence Synthesis. JBl; 2020. https://doi.org/10.46658/JBIMES-20-09.

19. Munn Z, Moola S, Lisy K, Riitano D, Tufanaru C. Chapter 5: Systematic reviews of prevalence and incidence. In: Aromataris E, Munn Z, editors. JBI Manual for Evidence Synthesis. JBI; 2020. https://doi.org/10.46658/ JBIMES-20-06.

20. Lucchetta R. Protocol: Prevalence of micronutrient deficiencies in women of childbearing age in Brazil: systematic review and metaanalysis. OSF. 2020. https://doi.org/10.17605/OSF.IO/J9QMH.

21. Hane PJ. Newsbreaks: Elsevier announces Scopus service. [Internet]. Inf Today 2004.2017 [cited 2017 Sep 13]. Available from: http://www.infotoday. com/newsbreaks/nb040315-1.shtml. Accessed in 2021 (Apr 23).

22. Munn Z, Stern C, Aromataris E, Lockwood C, Jordan Z. What kind of systematic review should I conduct? A proposed typology and guidance for systematic reviewers in the medical and health sciences. BMC Med Res Methodol. 2018;18(1):5. PMID: 29316881; https://doi.org/10.1186/ s12874-017-0468-4.

23. Team RC. R: A language and environment for statistical computing. [Internet]. Vienna, Austria: R Foundation for Statistical Computing. Available from: https://www.r-project.org/. Accessed in 2021 (Apr 23).
24. Wickham H, Hester J, François R. Readr: Read rectangular text data. R package version 1.1.1 [Internet]. 2017. Available from: https://cran.rproject.org/package=readr. Accessed in 2021 (Apr 23).

25. Schwarzer G. Meta: An R package for meta-analysis. R News. 2007;7(3):40-5. Available from: https://www.researchgate.net/ publication/285729385_meta_An_R_Package_for_Meta-Analysis. Accessed in 2021 (Apr 23).

26. Mahadev S, Laszkowska M, Sundström J, et al. Prevalence of Celiac Disease in Patients With Iron Deficiency Anemia-A Systematic Review With Meta-analysis. Gastroenterology. 2018;155(2):374-382.e1. PMID: 29689265; https://doi.org/10.1053/j.gastro.2018.04.016.

27. Munn Z, Moola S, Lisy K, Riitano D, Tufanaru C. Methodological guidance for systematic reviews of observational epidemiological studies reporting prevalence and cumulative incidence data. Int J Evid Based Healthc. 2015;13(3):147-53. PMID: 26317388; https://doi.org/10.1097/ XEB.0000000000000054

28. Migliavaca CB, Stein C, ColpaniV, et al. Quality assessment of prevalence studies: a systematic review. J Clin Epidemiol. 2020;127:59-68. PMID: 32679313; https://doi.org/10.1016/j.jclinepi.2020.06.039.

29. Gurgel CSS, Lira LQ de, Azevedo GM, et al. Comparação entre a concentração sérica de alfa-tocoferol de puérperas assistidas em maternidades públicas e privadas no Nordeste do Brasil. Rev Bras Ginecol e Obstet. 2014;36(8):372-6. http://dx.doi.org/10.1590/SO100-720320140005006.

30. Monteiro JP, Cruz ML, Mussi-Pinhata MM, et al. Vitamin A, vitamin E, iron and zinc status in a cohort of HIV-infected mothers and their uninfected infants. Rev Soc Bras Med Trop. 2014;47(6):692-700. PMID: 25626647; https://doi.org/10.1590/0037-8682-0226-2014.

31. Clemente HA, Ramalho HM, Lima MS, Grilo EC, Dimenstein R. Maternal supplementation with natural or synthetic vitamin $E$ and its levels in human colostrum. J Pediatr Gastroenterol Nutr. 2015;60(4):533-7. PMID: 25419678; https://doi.org/10.1097/MPG.0000000000000635.

32. Madruga de Oliveira A, Rondó PH, Barros SB. Concentrations of ascorbic acid in the plasma of pregnant smokers and nonsmokers and their newborns. Int J Vitam Nutr Res. 2004;74(3):193-8. PMID: 15296078; https://doi.org/10.1024/0300-9831.74.3.193.

33. da Silva Ribeiro KD, Lima MS, Medeiros JF, et al. Association between maternal vitamin E status and al pha-tocopherol levels in the newborn and colostrum. Matern Child Nutr. 2016;12(4):801-7. PMID: 26924492; https://doi.org/10.1111/mcn.12232.

34. Ribeiro KDS, Weigert L, Andrade T, Lima A, Medeiros J, Lima $M$, et al. The socioeconomic variables influence in the alphatocopherol concentration of the maternal serum. Rev Bras Saude Mater Infant. 2017;17(1):179-84. http://dx.doi.org/10.1590/1806930420170001000010

35. da Silva AGCL, de Sousa Rebouças A, Mendonça BMA, et al. Relationship between the dietary intake, serum, and breast milk concentrations of vitamin $\mathrm{A}$ and vitamin $\mathrm{E}$ in a cohort of women over the course of lactation. Matern Child Nutr. 2019;15(3):e12772. PMID: 30578660; https://doi.org/10.1111/mcn.12772. 
36. Rodrigues KDDSR. Estado nutricional em vitamina e de mães e crianças pré-termo e termo do nascimento aos 3 meses pós-parto [thesis]. Natal (RN): Universidade Federal do Rio Grade do Norte; 2016.

37. de Lira LQ, Ribeiro PPC, Grilo EC, Lima MSR, Dimenstein R. Níveis de alfa-tocoferol no soro e colostro de lactantes e associação com variáveis maternas. Rev Bras Ginecol Obstet. 2012;34(8):362-8. https:// doi.org/10.1590/S0100-72032012000800004.

38. Garcia L, Ribeiro K, Araújo K, et al. Alpha-tocopherol concentration in the colostrum of nursing women supplemented with retinyl palmitate and alpha-tocopherol. J Hum Nutr Diet. 2010;23(5):529-34. PMID: 20831709; https://doi.org/10.1111/j.1365-277X.2010.01063.x.

39. de Lira LQ, Lima MS, de Medeiros JM, da Silva IF, Dimenstein R. Correlation of vitamin A nutritional status on alpha-tocopherol in the colostrum of lactating women. Matern Child Nutr. 2013;9(1):31-40. PMID: 22099335; https://doi.org/10.1111/j.1740-8709.2011.00376.x.

40. Carr AC, Rowe S. Factors Affecting Vitamin C Status and Prevalence of Deficiency: A Global Health Perspective. Nutrients. 2020;12(7):1963. PMID: 32630245; https://doi.org/10.3390/nu12071963.

41. Hoppu U, Rinne M, Salo-Väänänen P, et al. Vitamin C in breast milk may reduce the risk of atopy in the infant. Eur J Clin Nutr. 2005;59(1):123-8. PMID: 15340369; https://doi.org/10.1038/sj.ejcn.1602048.

42. Lima MS, Dimenstein R, Ribeiro KD. Vitamin E concentration in human milk and associated factors: a literature review. J Pediatr (Rio J). 2014 SepOct;90(5):440-8. PMID:24953721; https://doi.org/10.1016/j.jped.2014.04.006.

43. do Nascimento MB, Issler $\mathrm{H}$. Breastfeeding: making the difference in the development, health and nutrition of term and preterm newborns. Rev Hosp Clin Fac Med Sao Paulo. 2003;58(1):49-60. PMID: 12754591; https://doi.org/10.1590/s0041-87812003000100010.

44. Guyatt $\mathrm{GH}$, Oxman $\mathrm{AD}$, Kunz R, et al. What is "quality of evidence" and why is it important to clinicians? BMJ. 2008;336(7651):995-8. PMID: 18456631; https://doi.org/10.1136/bmj.39490.551019.BE.

45. Glasziou P, Chalmers I, Rawlins M, McCulloch P. When are randomised trials unnecessary? Picking signal from noise. BMJ. 2007;334(7589):34951. PMID: 17303884; https://doi.org/10.1136/bmj.39070.527986.68.

46. Brasil. Ministério da Saúde. Secretaria de Ciência, Tecnologia, Inovação e Insumos Estratégicos em Saúde. Departamento de Assistência Farmacêutica e Insumos Estratégicos. Relação Nacional de Medicamentos Essenciais: Rename 2020 [recurso eletrônico]/ Ministério da Saúde, Secretaria de Ciência, Tecnologia, Inovação e Insumos Estratégicos em Saúde, Departamento de Assistência Farmacêutica e Insumos Estratégicos. Brasília: Ministério da Saúde; 2020. Available from: http://bvsms.saude.gov.br/bvs/publicacoes/ relacao_medicamentos_rename_2020.pdf. Accessed in 2021 (Apr 23).

47. Brasil. Ministério da Saúde. NutriSUS - Estratégia de fortificação da alimentação infantil com micronutrientes (vitaminas e minerais) em pó: manual operacional/Ministério da Saúde, Ministério da Educação. Brasília: Ministério da Saúde; 2015. Available from: http://bvsms.saude. gov.br/bvs/publicacoes/nutrisus_estrategia_fortificacao_alimentacao_ infantil.pdf. Accessed in 2021 (Apr 23).
48. Brasil. Ministério da Saúde. Secretaria de Atenção à Saúde. Departamento de Atenção Básica. Programa Nacional de Suplementação de Ferro: manual de condutas gerais/Ministério da Saúde. Secretaria de Atenção à Saúde. Departamento de Atenção Básica. Brasília: Ministério da Saúde; 2013. Available from: http:// bvsms.saude.gov.br/bvs/publicacoes/manual_suplementacao_ferro_ condutas_gerais.pdf. Accessed in 2021 (Apr 23).

49. Brasil. Ministério da Saúde. Secretaria de Atenção à Saúde. Departamento de Atenção Básica. Manual de condutas gerais do Programa Nacional de Suplementação de Vitamina A/Ministério da Saúde, Secretaria de Atenção à Saúde, Departamento de Atenção Básica. Brasília: Ministério da Saúde; 2013. https://bvsms.saude.gov.br/bvs/publicacoes/manual_ condutas_suplementacao_vitamina_a.pdf. Accessed in 2021 (Apr 23).

50. Rumbold A, Ota E, Nagata C, Shahrook S, Crowther CA. Vitamin C supplementation in pregnancy. Cochrane Database Syst Rev. 2015;(9):CD004072. PMID: 26415762; https://doi.org/10.1002/14651858. CD004072.

51. Le NK, Kesayan T, Chang JY, Rose DZ. Cryptogenic Intracranial Hemorrhagic Strokes Associated with Hypervitaminosis E and Acutely Elevated $\alpha$-Tocopherol Levels. J Stroke Cerebrovasc Dis. 2020;29(5):104747. PMID: 32151478; https://doi.org/10.1016/j. jstrokecerebrovasdis.2020.104747.

52. Tsai HH, Lin HW, Simon Pickard A, Tsai HY, Mahady GB. Evaluation of documented drug interactions and contraindications associated with herbs and dietary supplements: a systematic literature review. Int J Clin Pract. 2012;66(11):1056-78. PMID: 23067030; https://doi. org/10.1111/j.1742-1241.2012.03008.x.

53. Moura MRL, Reyes FGR. Interação fármaco-nutriente: uma revisão. Rev Nutr. 2002;15(2):223-38. http://dx.doi.org/10.1590/S141552732002000200011

Authors' contributions: Lucchetta RC: conceptualization (lead), data curation (lead), formal analysis (lead), funding acquisition (lead), investigation (lead), methodology (lead), project administration (equal), software (lead), supervision (equal), validation (equal), visualization (lead) and writing-original draft (lead); Cavicchioli SA: data curation (supporting), investigation (supporting), visualization (supporting) and writing-review and editing (supporting); Gini ALR: data curation (supporting), investigation (supporting), visualization (supporting) and writing-review and editing (supporting); Forgerini M: visualization (supporting) and writing-review and editing (supporting); Varallo FR: visualization (supporting) and writing-review and editing (supporting); de Nadai MN: visualization (supporting) and writing-review and editing (supporting); Fernandez-Llimos F: visualization (supporting) and writing-review and editing (supporting); and Mastroianni PC: conceptualization (equal), funding acquisition (equal), project administration (equal), supervision (equal), validation (equal), visualization (equal) and writing-review and editing (lead). All authors actively contributed to discussion of the results from the study, and reviewed and approved the final version to be released 
Sources of funding: This study was funded by Ministério da Ciência,

Tecnologia, Inovações e Comunicações (MCTIC), Ministério da

Saúde (MS) and Conselho Nacional de Desenvolvimento Científico

e Tecnológico (CNPq) (no. 26/2019, procedural no. 4426122019-2).

Additionally, this study was financed in part by the Coordenação de

Aperfeiçoamento de Pessoal de Nível Superior - Brasil (CAPES) - Finance

Code 001, and by Fundação de Amparo à Pesquisa do Estado de São

Paulo (FAPESP) (grant number 2018/07501-9)

Conflict of interest: The authors do not have any disclosures to report

Date of first submission: December 29, 2020

Last received: March 20, 2021

Accepted: April 9, 2021

Address for correspondence:

Patricia de Carvalho Mastroianni

Departamento de Fármacos e Medicamentos. Faculdade de Ciências

Farmacêuticas. Universidade Estadual Paulista “Júlio de Mesquita Filho" - UNESP

Rodovia Araraquara-Jáu, km 1 - s/no

Araraquara (SP) — Brasil

CEP 14801-902

Tel. (+55 16) 3301-6977

Fax. (+55 16) 3322-0073/3301-6960

E-mail: patricia.mastroianni@unesp.br 